\title{
DETERMINATION OF THE HOT DEFORMATION ACTIVATION ENERGY AND FLOW STRESS COURSE OF THE AISI 4140 STEEL
}

\author{
${ }^{1}$ Stanislav RUSZ, ${ }^{1}$ Filip GOLASOWSKI, ${ }^{1}$ Ivo SCHINDLER, ${ }^{1}$ Petr OPĚLA, ${ }^{2}$ Rostislav TUROŇ, \\ ${ }^{1}$ Rostislav KAWULOK, ${ }^{1}$ Vojtěch ŠEVČÁK, ${ }^{1}$ Petr KAWULOK \\ ${ }^{1}$ VSB - Technical University of Ostrava, Faculty of Meterials Science and Technology, Ostrava, Czech \\ Republic, EU, stanislav.rusz2@vsb.cz, ivo.schindler@vsb.cz, petr.opela@vsb.cz

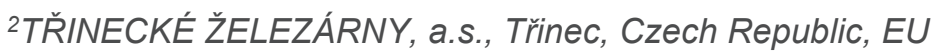

https://doi.org/10.37904/metal.2019.817

\begin{abstract}
The paper deals with the possibilities of the determination of the hot deformation activation energy and the flow stress course at hot forming conditions. By means of the Gleeble 3800 plastometer, the set of uniaxial compression tests has been carried out for the AISI 4140 steel. The tests were carried out within the temperature range of $850-1250{ }^{\circ} \mathrm{C}$ and the strain rate range of $0.1-50 \mathrm{~s}^{-1}$ when the strain reached up to 1.0. From the obtained stress - strain curves the values of peak stress were determined and subsequently used to determine the value of the activation energy at hot forming according to the classical equation of the hyperbolicsine type. Enumeration of its coefficients allow at the same time to predict the maximum flow-stress values of the investigated steel in dependence on the temperature and strain rate. The value of the activation energy has been used to assembly the mathematical models which allow to describe the flow stress course and the kinetics of the dynamic recrystallization of this steel at hot-forming conditions. By this way obtained results have been compared with the previously examined steel of the grade of AISI 4130.
\end{abstract}

Keywords: Stress - strain curves, hot deformation activation energy, AISI 4140 steel, uniaxial compression test

\section{INTRODUCTION}

The stress-strain curves serve for description of evolution of the flow stress in dependence on the strain, temperature and strain rate. It is very important to predict the material natural flow stress during hot forming, for example, for choosing the right tool for material forming. Such a prediction can be, however, complicated in the case of big strains where it is complicated by dynamic softening processes. A whole range of equations exists dealing with the mathematical description of stress curves [1,2]. The issue is phenomenologically addressed, for example, by the modified Fields and Backofen [3] model, or the complicated model designed by Hensel and Spittel [4], incorporated together with the relevant material database, into, for example, the popular FORGE simulation software. The mathematical models with a physical basis are mostly based on the description of the peak-stress coordinates, possibly also the coordinates of the point corresponding to the beginning of the steady-state flow - see for example [5,6]. Many authors approach to separate descriptions of different parts of the stress-strain curve by separate equations - see for example [7,8]. Activation energy is an important material constant for hot forming, which depends on the chemical composition and material microstructure. It is used, for example for prediction of the stress peak point, i.e. of the maximum flow stress and the beginning of the dynamic recrystallization of material formed under the given thermo-mechanical conditions. These tests will then provide the appropriate data for calculating the activation energy, which is calculated from the relationship (1) derived from the Garofalo's equation [9].

$\dot{e}=C \cdot \exp \left(\frac{-Q}{R \cdot T}\right) \cdot\left[\sinh \left(\alpha \cdot \sigma_{\max }\right)\right]^{n}$

where $\dot{e}$ - strain rate $\left(\mathrm{s}^{-1}\right), Q$ - activation energy $\left(\mathrm{J} \cdot \mathrm{mol}^{-1}\right), R$ - specific gas constant $8.314\left(\mathrm{~J} \cdot \mathrm{mol}^{-1} \cdot \mathrm{K}^{-1}\right)$,

$T$ - temperature $(\mathrm{K}), \sigma_{\max }$ - natural flow stress in the peak (MPa), $C$ - material constant $\left(\mathrm{s}^{-1}\right)$,

$\alpha$ - material constant $\left(\mathrm{MPa}^{-1}\right), n$ - material constant (-) 
The coordinates of the characteristic points of the flow curves (peak point, steady-state origin, etc.) are determined by subtracting from the experimental flow curves compiled for specific combinations of temperatures and strain rates. C. Zener and J. H. Hollomon have proposed a parameter that allows combining the effect of temperature and strain rate on the flow stress level. This parameter thus represents the so-called temperature-compensated strain rate. The Zener-Hollomon parameter $Z\left(\mathrm{~s}^{-1}\right)$ is then expressed by the following relationship [10]:

$Z=\dot{e} \cdot \exp \left(\frac{Q}{R \cdot T}\right)$

where $\dot{e}\left(\mathrm{~s}^{-1}\right)$ is the strain rate and $T(\mathrm{~K})$ is the thermodynamic temperature of the deformation. $R\left(8.314 \mathrm{~J} \cdot \mathrm{K}^{-1} \cdot \mathrm{mol}^{-1}\right)$ represents the universal gas constant and $Q\left(\mathrm{~J} \cdot \mathrm{mol}^{-1}\right)$ represents the so-called activation energy at hot forming. Thanks to the knowledge of Zener-Hollomon parameter it is possible to determine the coordinates of the peak point of flow curves $\left(e_{p}\right.$ a $\left.\sigma_{\max }\right)$ and thus the beginning of dynamic recrystallization can be predicted. The maximum flow stress value $\sigma_{\max }(\mathrm{MPa})$ can be calculated according to the following relation (3) and the peak strain $e_{p}$ according to (4):

$\sigma_{\max }=\frac{1}{\alpha} \cdot \operatorname{arc} \sinh \sqrt[n]{\frac{z}{c}}$

$e_{p}=U \cdot Z^{W}$

where $U(\mathrm{~s})$ and $W(-)$ are material constants.

The main objective was to determine the value of the hot activation energy of AISI 4140 steel and to compare it to AISI 4130 steel. Simple equations were derived allowing rapid prediction of both peak point coordinates in dependence on temperature-compensated strain rate, i.e. the maximum natural flow stress and strain corresponding to the onset of dynamic recrystallization. The next goal was to describe the stress-strain curves of AISI 4140 by two uniform models - with a complex phenomenological and a simpler one with a physical basis. Both equations reflect the effect of dynamic recrystallization and allow prediction of the natural flow stress up to strain 1 , in the temperature range of $850^{\circ} \mathrm{C}$ to $1250^{\circ} \mathrm{C}$ and the strain rate range of $0.1 \mathrm{~s}^{-1}$ to min. $50 \mathrm{~s}^{-1}$.

\section{DESCRIPTION OF EXPERIMENT}

The experiment was performed on samples from AISI 4140 steel obtained from Třinecké železárny a.s. in a post-hot-rolling state. The chemical composition can be seen in Table 1. Samples of $\varnothing 10 \times 15 \mathrm{~mm}$ were resistively heated and deformed by uniaxial compression to the strain of 1 on the Hydrawedge II simulator module of the Gleeble 3800 plastometer. Heating at the rate of $5{ }^{\circ} \mathrm{C} / \mathrm{s}$ was applied directly at the deformation temperature (850 - $\left.960-1090-1250{ }^{\circ} \mathrm{C}\right)$, with the dwell-time of $300 \mathrm{~s}$, followed by forming at nominal strain rates $\left(0.1-0.8-6-50 \mathrm{~s}^{-1}\right)$. The recorded stress-strain curves in a raw state, that is, without preliminary smoothing - were used for the subsequent mathematical processing. Both coordinates of the peak point were localized for each curve. The $\sigma_{\max }$ values were used to determine the constants in the relationship (1) through the proven interactive ENERGY 4.0 software. The curve courses for selected temperatures are shown in Figures 1 - 2.

Table 1 Chemical composition of AISI 4140 steel and comparison with AISI 4130 in mass \%.

\begin{tabular}{|c|c|c|c|c|c|c|c|c|}
\hline & $\mathrm{C}$ & $\mathrm{Si}$ & $\mathrm{Mn}$ & $\mathrm{Cr}$ & $\mathrm{Mo}$ & $\mathrm{Ni}$ & $\mathrm{P}$ & $\mathrm{S}$ \\
\hline $\mathrm{AISI} 4140$ & $0.36-0.44$ & $0.1-0.4$ & $0.65-1.1$ & $0.9-1.2$ & $0.15-0.35$ & $0-0.3$ & $0-0.04$ & $0-0.04$ \\
\hline $\mathrm{AISI} 4130$ & $0.28-0.33$ & $0.1-0.35$ & $0.4-0.6$ & $0.7-1.1$ & $0.15-0.35$ & $0-0.25$ & $0-0.035$ & $0-0.04$ \\
\hline
\end{tabular}




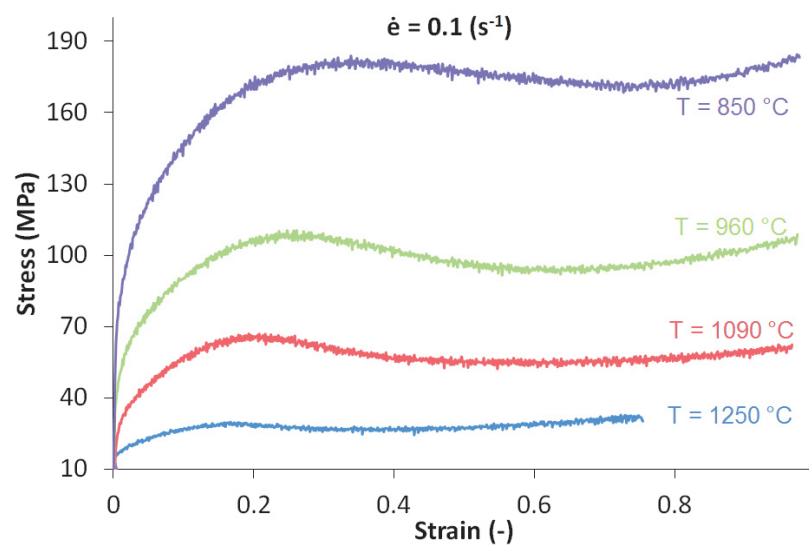

Figure 1 Stress-strain curves at selected deformation temperatures

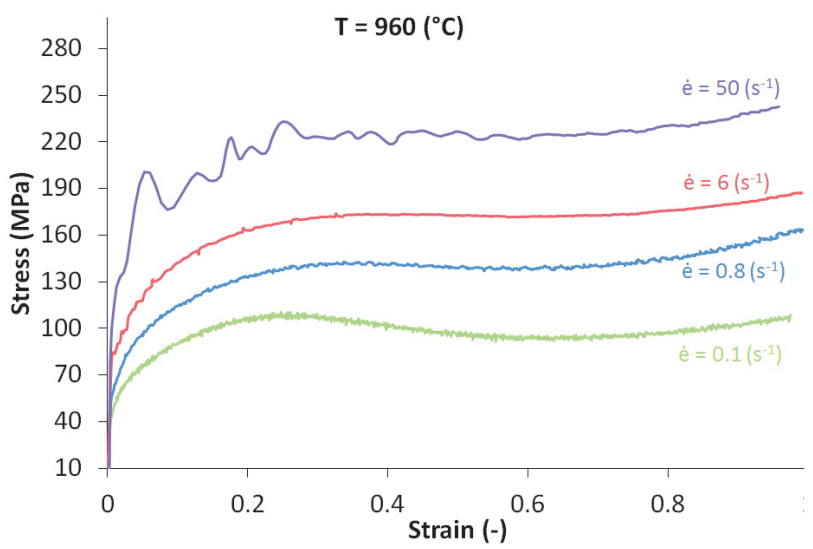

Figure 2 Stress-strain curves at selected strain rate

\section{CALCULATION OF THE ACTIVATION ENERGY}

A special software "ENERGY" was developed for calculation of activation energy at hot forming and for description of kinetics of dynamic recrystallization. This software ENERGY in the version of 4.0 works in two modes (manual and automatic). The manual mode evaluates the data on the basis of linear regressions. The automatic mode refines more precisely the results obtained in the manual mode using the method of least squares on the basis of non-linear regressions. The values of the maximum flow stress $\sigma_{\max }$ and the strain rate values at a given temperature serve as input data for calculating the activation energy.

The results of activation energy calculation and the corresponding constants can be seen in Table 2. The activation energy of AISI 4140 is slightly higher than that of AISI 4130 [11]. The higher activation energy is due to a greater proportion of carbon and manganese. We must, however, take into account, that the AISI 4130 steel has not been tested under the same temperature conditions.

Table 2 Q-value comparison between the selected steels

\begin{tabular}{|c|c|c|}
\hline & AISI 4130 & AISI 4140 \\
\hline$Q\left(\mathrm{~J} \cdot \mathrm{mol}^{-1}\right)$ & 383 & 392 \\
\hline$n(-)$ & 4.7 & 5.62 \\
\hline$\alpha\left(\mathrm{MPa}^{-1}\right)$ & 0.012 & 0.0087 \\
\hline$C\left(\mathrm{~s}^{-1}\right)$ & $2.2 \mathrm{E}+14$ & $2.05 \mathrm{E}+15$ \\
\hline$U(\mathrm{~s})$ & 0.018 & 0.189 \\
\hline$W(-)$ & 0.08 & 0.016 \\
\hline
\end{tabular}

In Figure 3, the experimental values of $\sigma_{\max }$ and $e_{p}$ of the AISI 4140 steel are compared with the values which were calculated using the equations (2), (3) and (4) and the obtained coefficients. The accuracy of peak stress localization on the specific experimental stress-strain curve is always higher than the determination of $e_{p}$ strain, and therefore the better match of predicted and experimental data in the case of $\sigma_{\max }$ is not surprising. The correlation coefficient for $\sigma_{\max }$ is $R=0.997$ and $e_{p}=0.669$.

Using the results of regression analysis in the automatic mode of the ENERGY 4.0 program, 3D graphs were created, which are shown in Figures 4 and $\mathbf{5}$. Figure 4 confirms that with increasing temperature and decreasing strain rate, the stress decreases. 


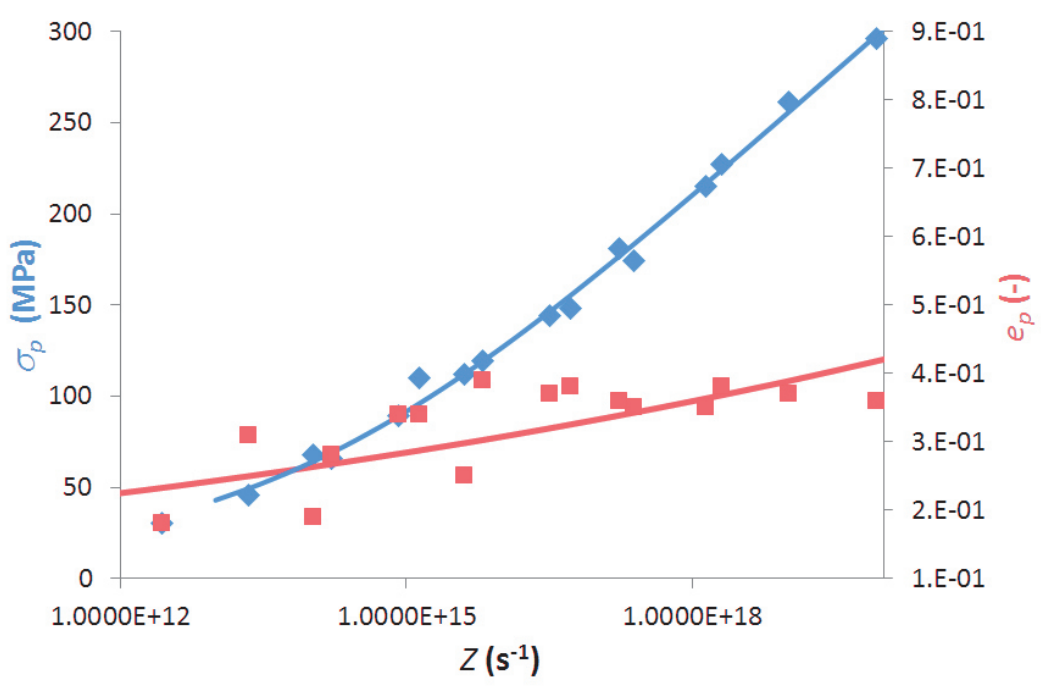

Figure 3 Dependence of peak point coordinates on the Zener-Hollomon parameter (points - experiment; lines -calculations)

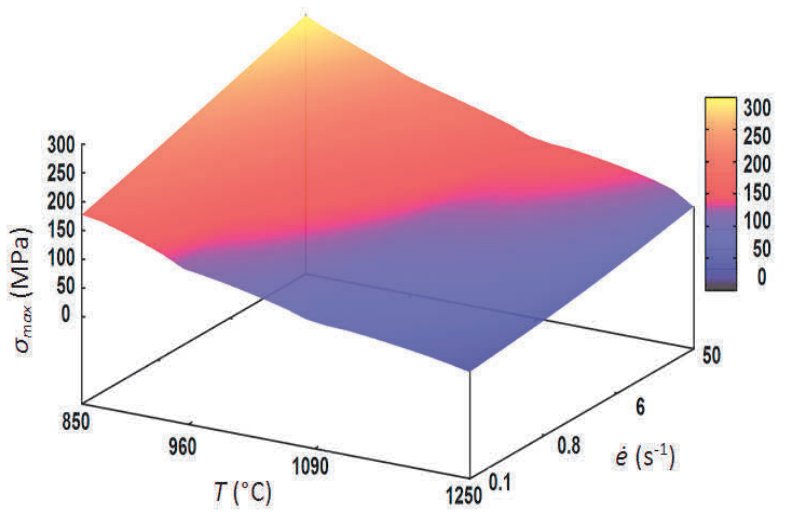

Figure 4 Spatial dependence of the calculated maximum stress on the temperature and nominal strain rate

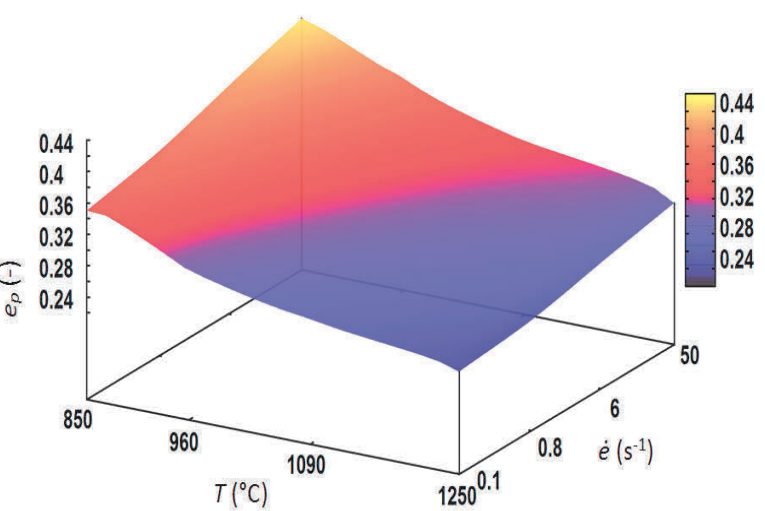

Figure 5 Spatial dependence of the calculated peak strain on the temperature and nominal strain rate

\section{MATHEMATICAL DESCRIPTION OF THE NATURAL FLOW STRESS}

To describe the flow curves, two models were selected with the ability to describe flow curves over the entire range of strains. The first model to predict flow stress is the model of A. Hensel and T. Spittel (H-S), which is implemented in FEM simulation software FORGE®. Its form for the prediction of hot flow stress is as follows [4]:

$\sigma=K_{1} \cdot e^{n} \cdot \exp \left(\frac{K_{2}}{e}\right) \cdot(1+e)^{K_{3} \cdot t} \cdot \exp \left(K_{4} \cdot e\right) \cdot \exp (P \cdot t) \cdot t^{p} \cdot \dot{e}^{M_{1}} \cdot \dot{e}^{M_{2} \cdot t}$

Obviously, the model (5) is quite complicated. It includes a total of four strain components (two power and two exponential), ensuring the desired shape change of the flow curve with the strain e (-). In addition, it includes two terms (power and exponential), reflecting the influence of the deformation temperature $t\left({ }^{\circ} \mathrm{C}\right.$ ) on the flow stress $\sigma(\mathrm{MPa})$ and also two power terms reflecting the influence of the strain rate $\dot{e}\left(\mathrm{~s}^{-1}\right)$. The main advantage of the model (5) is its ability to describe a set of flow curves uniformly over almost the entire range of strains through a single functional prescription and one set of material constants. The prediction option is limited only 
in the region of very low strains (for $e<0.04$ ). Its main drawback is that it does not include any of the characteristic points of flow curves.

The I. Schindler, J. Kliber and J. Bořuta (S-K-B) model was chosen as the second model. The model reliably describes the flow curves in the area of strains up to the peak $e_{p}$ and partly also in the area of predominant softening up to the value of the so-called inflection point $e_{i}(-)$ (which is located between the peak strain $e_{p}$ and the beginning of the steady-state flow $\left.e_{s s}(-)\right)$ and has the following form [12]:

$\sigma=K \cdot e^{n} \cdot \exp \left(-n \cdot \frac{e}{e_{p}}\right) \cdot \dot{e}^{\left(M_{1}-\frac{M_{2}}{T}\right)} \cdot \exp (-P \cdot T)$

The model (6) has two strain components. The first one, $e^{n}$, provides an increase of flow stress up to the peak $e_{p}(-)$ and the second one, $\exp \left(-n \cdot\left(e / e_{p}\right)\right)$, mediating the exponential decrease of the flow stress beyond the peak-point value, thus reflecting the consequences of the dynamic recrystallization process.

Using of demanding nonlinear regression analysis in UNISTAT 6.5 statistical software, material constants of the above-mentioned models were been obtained for the examined AISI 4140 steel in order to calculate flow stress in dependence on strain, strain rate and temperature. The calculated constants for both equations are shown in Table 3.

Table 3 Calculation of constant for equations (5) and (6)

\begin{tabular}{|c|c|c|c|c|c|c|c|c|c|}
\hline \multirow{2}{*}{ H-S (5) } & 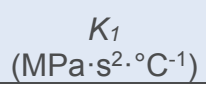 & $\begin{array}{l}K_{2} \\
(-)\end{array}$ & $\begin{array}{c}K_{3} \\
\left({ }^{\circ} \mathrm{C}^{-1}\right) \\
\end{array}$ & $\begin{array}{l}K_{4} \\
(-)\end{array}$ & $\begin{array}{l}M_{1} \\
(-)\end{array}$ & $\begin{array}{c}\mathrm{M}_{2} \\
\left({ }^{\circ} \mathrm{C}^{-1}\right)\end{array}$ & $\begin{array}{c}n \\
(-)\end{array}$ & $\begin{array}{c}P \\
\left({ }^{\circ} \mathrm{C}^{-1}\right)\end{array}$ & $\begin{array}{c}p \\
(-)\end{array}$ \\
\hline & 1722.84 & -0.0125 & -0.0002 & -0.1456 & -0.2163 & 0.0003 & 0.1069 & -0.0041 & 0.2484 \\
\hline \multirow{2}{*}{ S-K-B (6) } & $\begin{array}{c}K \\
\text { (MPa.s) }\end{array}$ & $\begin{array}{l}M_{1} \\
(-)\end{array}$ & $\begin{array}{l}M_{2} \\
(\mathrm{~K})\end{array}$ & $\begin{array}{c}n \\
(-)\end{array}$ & $\underset{\left(\mathrm{K}^{-1}\right)}{P}$ & & & & \\
\hline & $16,996.99$ & 0.5328 & 520.3416 & 0.2031 & 0.0035 & & & & \\
\hline
\end{tabular}

As shown in the graphs in Figures 6-7, the real accuracy of the derived equations (5) and (6) is more or less the same. The simpler physically-based S-K-B model responds better to changes in $e_{p}$ size with varying Zvalue and is applicable even for very small deformations. From the values of the determination coefficients (0.989 and 0.994 for the model S-K-B and H-S, respectively), somewhat higher accuracy of the H-S model could be derived.

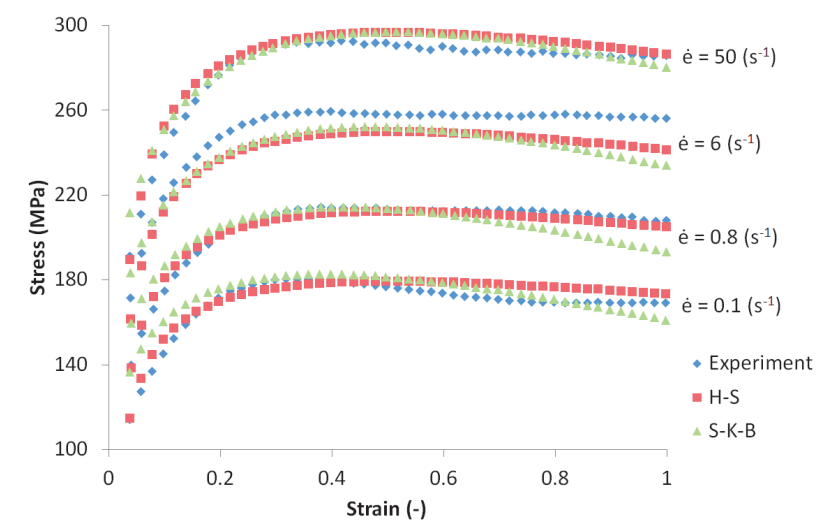

Figure 6 Comparison of accuracy of the H-S (5) and S-K-B (6) model with experimental data $\left(\mathrm{T}=850^{\circ} \mathrm{C}\right)$

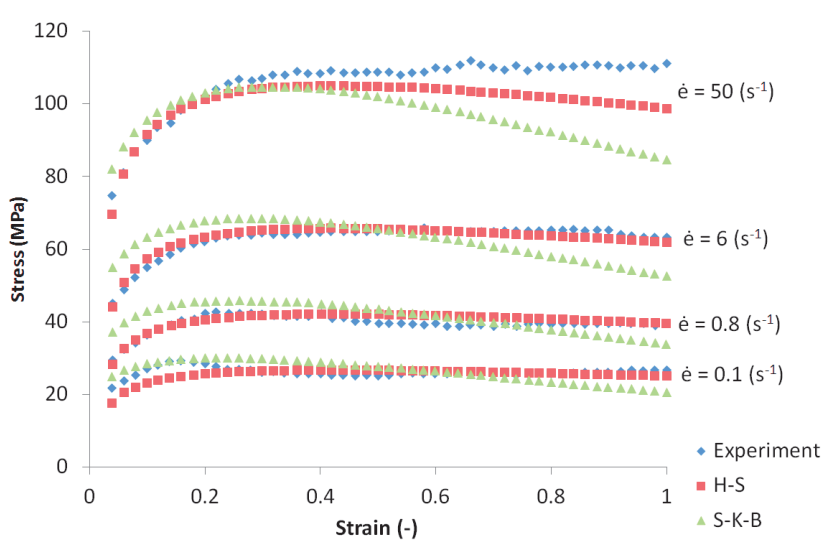

Figure 7 Comparison of accuracy of the H-S (5) and S-K-B (6) model with experimental data

$$
\left(\mathrm{T}=1250^{\circ} \mathrm{C}\right)
$$




\section{CONCLUSION}

Based on the analysis of experimental data, the value of the activation energy for hot forming $392 \mathrm{~kJ} \cdot \mathrm{mol}^{-1}$ was determined for AISI 4140 steel, which is a higher value than the comparative activation energy of $383 \mathrm{~kJ}$. mol-1 $^{-1}$ for AISI 4130 steel with a lower carbon and manganese content.

Simple equations were derived, enabling fast prediction of both peak point coordinates in the case of AISI 4140 steel, depending on the temperature-compensated strain rate, i.e. the maximum natural flow stress and strain corresponding to the onset of dynamic recrystallization.

The stress-strain curves of AISI 4140 steel have been described with good accuracy by two uniform models a complex phenomenological and a simpler one with a physical basis. Both equations reflect the influence of dynamic recrystallization and allow prediction of natural flow stress in the temperature range of 850 to $1250{ }^{\circ} \mathrm{C}$ and strain rates of 0.1 to $50 \mathrm{~s}^{-1}$, respectively.

\section{ACKNOWLEDGEMENTS}

The paper was created thanks to the project No. CZ.02.1.01/0.0/0.0/17_049/0008399 from the EU and $C R$ financial funds provided by the Operational Programme Research, Development and Education, Call 02_17_049 Long-Term Intersectoral Cooperation for ITI (Managing Authority: Czech Republic Ministry of Education, Youth and Sports), as well as the student grant projects SP2019/86 and SP2019/43 (VŠB-TU Ostrava).

\section{REFERENCES}

[1] JONAS, J. J., SELLARS, C. M., TEGART, W. J. McG. Strength and structure under hot-working conditions. Metallurgical Reviews. 1969, vol. 14, pp. 1-24.

[2] HOSFORD, W. F. and CADDELL, R. M. Metal Forming: Mechanics and Metallurgy, $4^{\text {th }}$ ed. New York: Cambridge University Press, 2011. p. 311.

[3] FIELDS, D. S. and BACKOFEN, W. A. Determination of strain hardening characteristics by torsion testing. Proceedings-American Society of Testing Materials. 1957, vol. 57, pp. 1259-1272.

[4] HENSEL, A. and SPITTEL, T. Kraft- und Arbeitsbedarfbildsamer Formgebungsverfahren. 1st ed. Leipzig: Deutscher Verlag für Grundstoffindustrie. 1978. p. 528.

[5] WU, L., et al. Predicting Critical Conditions and Stress-Strain Curves for Dynamic Recrystallization in SPHC Steel. Journal of Iron and Steel Research International. 2010, vol. 17, pp. 51-57.

[6] EBRAHIMI, R., ZAHIRI, S. H. and NAJAFIZADEH, A. Mathematical modelling of the stress-strain curves of Ti-IF steel at high temperature. Journal of Materials Processing Technology. 2006, vol. 171, pp. 301-305.

[7] OPĚLA, P., et al. New Model Predicting Flow Curves in Wide Range of Thermomechanical Conditions of 38MnVS6 Steel. In: Metal 2016: 25th Anniversary International Conference on Metallurgy and Materials. Ostrava: Tanger Ltd, 2017, pp. 458-463.

[8] SHENG, Z. Q. and SHIVPURI, R. Modeling flow stress of magnesium alloys at elevated temperature. Materials Science and Engineering: A. 2006, vol. 419, pp. 202-208.

[9] GAROFALO, F. An Empirical Relation Defining the Stress Dependence of Minimum Creep Rate in Metals. Transactions of the Metallurgical Society of AIME. 1963, vol. 227, pp. 351-356.

[10] ZENER, C. and J. H. HOLLOMON. Effect of Strain Rate Upon Plastic Flow of Steel. Journal of Applied Physics. 1944, vol. 15, pp. 22-32.

[11] SCHINDLER, I. et al. Přirozený deformační odpor a aktivační energie oceli 25CrMo4 při tváření za tepla. Kovárenství. 2018, vol. 64, pp. 18-21.

[12] SCHINDLER, I. and BOŘUTA, J. Deformační odpory ocelí při vysokoredukčním tváření za tepla. Hutnické listy. 1995, vol. 50, pp. 47-50. 